\title{
MARINE PALYNOLOGY IN PROGRESS
}

One of the things which the Second International Conference on Palynology (held in Utrecht, August 29-September 3, 1966) revealed, was the rapid expansion which marine palynological research has undergone in recent years. This was the main stimulus to organize this special issue of Marine Geology. It is good to have a number of valuable contributions to marine palynology together under one cover. It is also most useful that a wide range of marine geo-scientists are supplied with an evaluation and exemplary problems demonstrating some of the possibilities and limitations of pollen analysis of marine sediments.

Spore and pollen analysis of samples taken from marine sediments is the only universal method through which these sediments can be correlated with sediments that are found on the surrounding land. Of course, there are differences between pollen diagrams from continental and marine deposits but these do not generally prevent the establishment of correlations. The spectra from marine samples, particularly those from the deep-sea or other localities more distant from shore, represent some portions of a regional vegetation, in which local differences are subordinated. In the same way most short-time vegetational changes are not reflected, because the samples from which the required number of pollen grains have to be recovered, generally cover a time span of several hundreds of years. Further, there are often quantitative differences in the composition of the spectra; those from marine environments may, for example, contain more pine pollen and have a lower percentage of pollen from broadleaved trees and grasses.

For the palynologist, historical geologist, palaeoecologist and palaeoclimatologist, the greatest value of marine palynology lies in the unique chance to obtain a continuous record of major vegetational and climatic changes over a considerable span of time. The slow and continuous rain of fine sedimentary particles, hard parts of chemically and/or physically resistant parts of marine microorganisms, pollen grains and spores, and other plant detritus, provides an ideal recording mechanism. It is a well-known fact that no sedimentary succession in any continental area is complete and undisturbed. Thus, because of the nature of the depositional process, the deposits left on the continents by the Pleistocene glaciations provide a discontinuous record at best. To make matters more complex, disturbance by later glaciations has often garbed the earlier part of the record, and melt water, rivers and dust storms have eroded the deposits selectively in Late Glacial time. Although some discontinuities in the record of pollen, spores and similar entities in marine sediments do occur, there are certainly fewer of these than in terrestrial glacial deposits and they are easier to overcome.

A major problem in the palynological investigation of marine deposits is 
presented by the common occurrence of reworked pollen and spores. In each case the nature and extent of contamination should be carefully studied. Whereas this often may seem not to be too difficult when there is a great age difference between recycled and primary pollen and spores, it is generally only with extreme difficulty that pollen and spores are recognized which are deposited in a second cycle of sedimentation of any slightly younger age than primary deposition. It is good to see that most marine palynologists are very well aware of the problem of pollen redeposition and work hard to solve the questions of occurrence and recognition of secondary deposited plant microfossils. In some instances this may delay reaching the stage of deriving interpretations from the obtained pollen diagrams, but this is always better than running the risk of making and publishing erroneous conclusions.

It need hardly be said that the palynological analysis of marine sediments should preferably be used together with other kinds of investigations, such as mineralogical, sedimentological and geochemical analyses, studies of zoomicrofossils, radioactive-age determinations, etc. Combined studies always give a more reliable and detailed picture.

The Editor is grateful to all contributors to this issue for their pleasant cooperation. It is hoped that many readers, comprising both palynologists and marine geologists, will find the final product enlightening and stimulating. We will be happy to receive any comments, additional data and criticism that may arise from the reading of this special issue. We will be pleased to include a discussion of these in one of the subsequent issues of this journal.

A. A. Manten (Utrecht) 